University of Wisconsin Milwaukee

UWM Digital Commons

Geography Faculty Articles

Geography

9-2018

\title{
Climate Change and Nighttime Heat Stress: Tales of Two Cities in the U.S. Midwest
}

Woonsup Choi

University of Wisconsin-Milwaukee, choiw@uwm.edu

Follow this and additional works at: https://dc.uwm.edu/geog_facart

Part of the Geography Commons

\section{Recommended Citation}

Originally published in Journal of Climate Research, 2018, vol. 13, no. 3, pp. 197-210. DOI: 10.14383/cri.2018.13.3.197

This Article is brought to you for free and open access by UWM Digital Commons. It has been accepted for inclusion in Geography Faculty Articles by an authorized administrator of UWM Digital Commons. For more information, please contact open-access@uwm.edu. 


\section{미국 중서부 두 도시를 사례로 본 기후변화와 밤시간 열스트레스}

최운섭

밀워키위스콘신대학교 지리학과

Climate Change and Nighttime Heat Stress: Tales of Two Cities in the US

Midwest

\section{Woonsup Choi}

Department of Geography, University of Wisconsin-Milwaukee

Correspondence: Woonsup Choi, Department of Geography, University of Wisconsin-Milwaukee, PO Box 413, Milwaukee, Wisconsin, 53201-0413, USA, Email: wchoi@alumni.illinois.edu

Note: the published version of this article is available at http://jcr.re.kr (Journal of Climate Research, 2018, vol. 13, no. 3, pp. 197-210) 


\section{Abstract}

This study explores nighttime heat stress in two Midwestern regions in the United States, encompassing the cities of Minneapolis and Milwaukee. Daily minimum temperature data were obtained from the MACAv2-METDATA dataset at a 4-km resolution. Data were downloaded both for the historical (19502005) and RCP (Representative Concentration Pathways) 4.5 (2006-2099) simulations from 11 global climate models. MODIS land cover data at a 5'x5' resolution were used to delineate urban and non-urban areas. Heat stress was indicated by the occurrence of hot nights in two ways. First, the number of days with daily minimum temperatures above $300 \mathrm{~K}\left(27^{\circ} \mathrm{C}\right)$ was counted to calculate decadal frequency. Second, the $95^{\text {th }}$ percentile of daily minimum temperatures in the historical period was used as a threshold to calculate the duration of hot nights. The study finds that (1) hot nights $(>300 \mathrm{~K})$ are practically non-existent in the historical simulation but are likely to occur typically 2-3 times per decade with the RCP4.5 simulations; (2) the frequency of such events in the future can exceed 25 per decade in urban areas whereas it can be just about 1 per decade in non-urban areas depending on models; and (3) hot nights ( $>95^{\text {th }}$ percentile threshold) are likely to last longer in the future simulations. Overall, heat stress is projected to increase both in frequency and duration, and the urban heat island effect in terms of heat stress is projected to intensify in the future.

Key words: heat stress, urban heat island, climate change, temperature extreme 


\section{Introduction}

High temperatures in nighttime can cause sleep disturbance to human beings, which can affect their daytime activities (Okamoto-Mizuno and Mizuno 2012). The impact is particularly acute to those who do not have air-conditioners or cannot afford to use them, and urban residents are likely to be affected more than rural residents because of the urban heat island effects (Oleson et al. 2015, Ma et al. 2018). In particular, nighttime extreme high temperatures may pose a higher risk of mortality than daytime and leave urban residents subject to indoor heat and humidity without air conditioning (Zhao et al. 2018). As the worldwide heat wave in the summer of 2018 exposed, heat is the "next big inequality issue" (Fleming et al. 2018). Because of the projected demographic and climatic trends, heat stress is likely to continue to be an important health concern in the United States (Uejio et al. 2011). Therefore, it is of great necessity to assess nighttime heat stress in the context of urban heat island at diverse spatial scales and locations.

It is well known that the temperature regime will become more extreme in the middle and late $21^{\text {st }}$ century (Meehl and Tebaldi 2004, Meehl et al. 2007, Kirtman et al. 2013). Therefore, the characteristics of heat stress or heat waves will certainly change with the changing climate, as demonstrated by recent studies (Oleson et al. 2015, Kim et al. 2016, Mora et al. 2017, Wouters et al. 2017, Guerreiro et al. 2018, Li et al. 2018, Lopez et al. 2018). A heat wave generally refers to a period of extreme and unusual warmth but has various quantitative definitions (Smith, Zaitchik, and Gohlke 2013). Heat stress appears to have connotations of human health, and like heat waves, is quantitatively differently defined in different studies (e.g. Argueeso et al. 2015, Oleson et al. 2015, Wouters et al. 2017). This study is more oriented to heat stress rather than heat wave, in a sense that it focuses on the statistical characteristics of high temperatures but not individual heat wave events. In the United States, urban heat waves are projected to become more intense, longer, and frequent in the late $21^{\text {st }}$ century (Oleson et al. 2018). Nighttime heat stress is also projected to intensify under climate change conditions, more in urban areas than in rural areas around the world (Fischer, Oleson, and Lawrence 2012). However, in-depth studies at regional or local scales (e.g. Argueeso et al. 2015) are needed for appropriate adaptation measures.

Regional- or local-scale studies for climate change impacts on heat stress generally require historical and future climate data of sufficiently high spatial resolutions, but their availability varies by location. Even regional climate modeling or reanalysis data (Choi 2008) are still too coarse for examining heat stress in urban areas (Argueeso et al. 2015). Some previous studies on climate change and heat stress in cities used high-resolution (i.e. in the order of kilometers) monthly downscaled global climate models data across China (Li et al. 2018) or regional climate modeling for the Sydney region (Argueeso et al. 2015) and Belgium (Wouters et al. 2017). For the conterminous United States, daily downscaled global climate models data are available at a 4-km resolution, namely Multivariate Adapted Constructed Analogs (MACA) dataset (Abatzoglou and Brown 2012). Because regional climate modelling is still computationally expensive, such a dataset with high temporal and spatial resolutions from a range of climate models is appealing.

The present study utilizes the MACA dataset to examine nighttime heat stress for mid-sized cities in the US Midwest. The overarching research question is how useful the dataset is for research on heat stress and climate change in the context of urban heat island. In particular, this study aims to answer the following research questions: (1) What are the projected changes in heat stress with climate change in mid-sized cities in the US Midwest? and (2) How does the heat stress differ between urban and non-urban areas? This study contributes to the literature by shedding light on the issue for less studied areas and providing an information basis for studying demographic and socio-economic impacts. 


\section{Study area}

This study focuses on southeastern parts of Wisconsin and Minnesota encompassing metropolitan areas of Milwaukee (MKE) and Minneapolis-St. Paul (MSP), respectively (Figure 1). The study areas are in the core and periphery regions in the Great Lakes heat wave cluster (Lopez et al. 2018), and were studied for urban temperatures using the 32-km resolution North American Regional Reanalysis data (Choi, Keuser, and Becker 2012). This study is meant to expand on the studies using finer-resolution data.

The city of Milwaukee in Wisconsin is the largest city in the state with a population of almost 600,000 and surrounded by several suburban communities. The U.S. Census-designated metropolitan statistical area had a population of more than 1.3 million in 2010. The MSP metropolitan area comprises the cities of Minneapolis, St. Paul, and other smaller communities and is also the largest metropolitan area in the state of Minnesota. The metropolitan statistical area's population exceeded 2.6 million in 2010.

Climate of the region is characterized by mild summers and cold winters. In Milwaukee during 19712000, daily mean temperature in July slightly exceeded $21^{\circ} \mathrm{C}$ and that in January was below $-4{ }^{\circ} \mathrm{C}$. August was the wettest month with more than $100 \mathrm{~mm}$ of precipitation and February was the driest with less than $50 \mathrm{~mm}$ (Young 2007). In Minneapolis during 1981-2000, July temperature exceeded $23{ }^{\circ} \mathrm{C}$ but January temperature was below $-9{ }^{\circ} \mathrm{C}$. August and February were the wettest and driest months with precipitation of $109 \mathrm{~mm}$ and $19 \mathrm{~mm}$, respectively (National Climatic Data Center n.d.). 


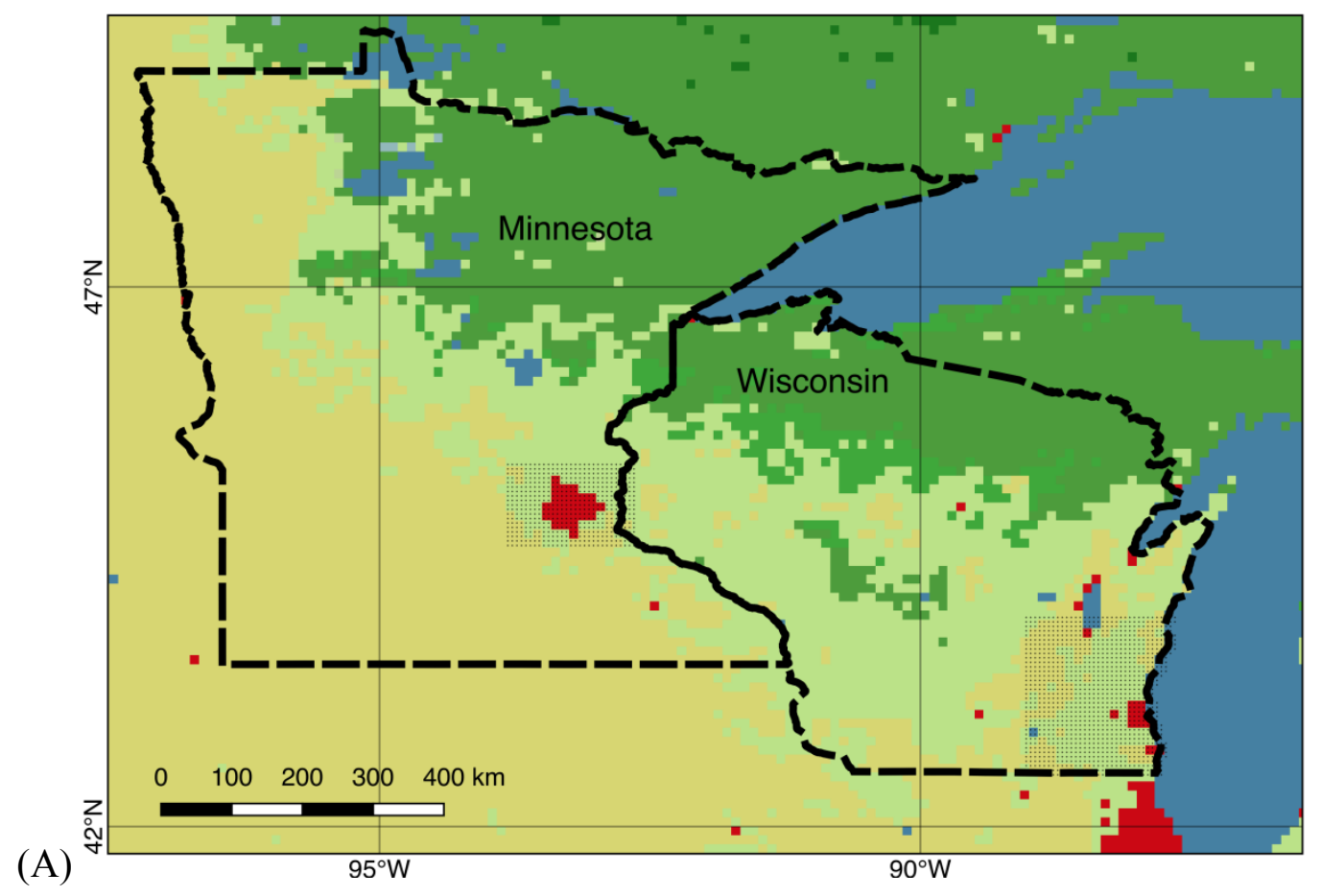

(A)
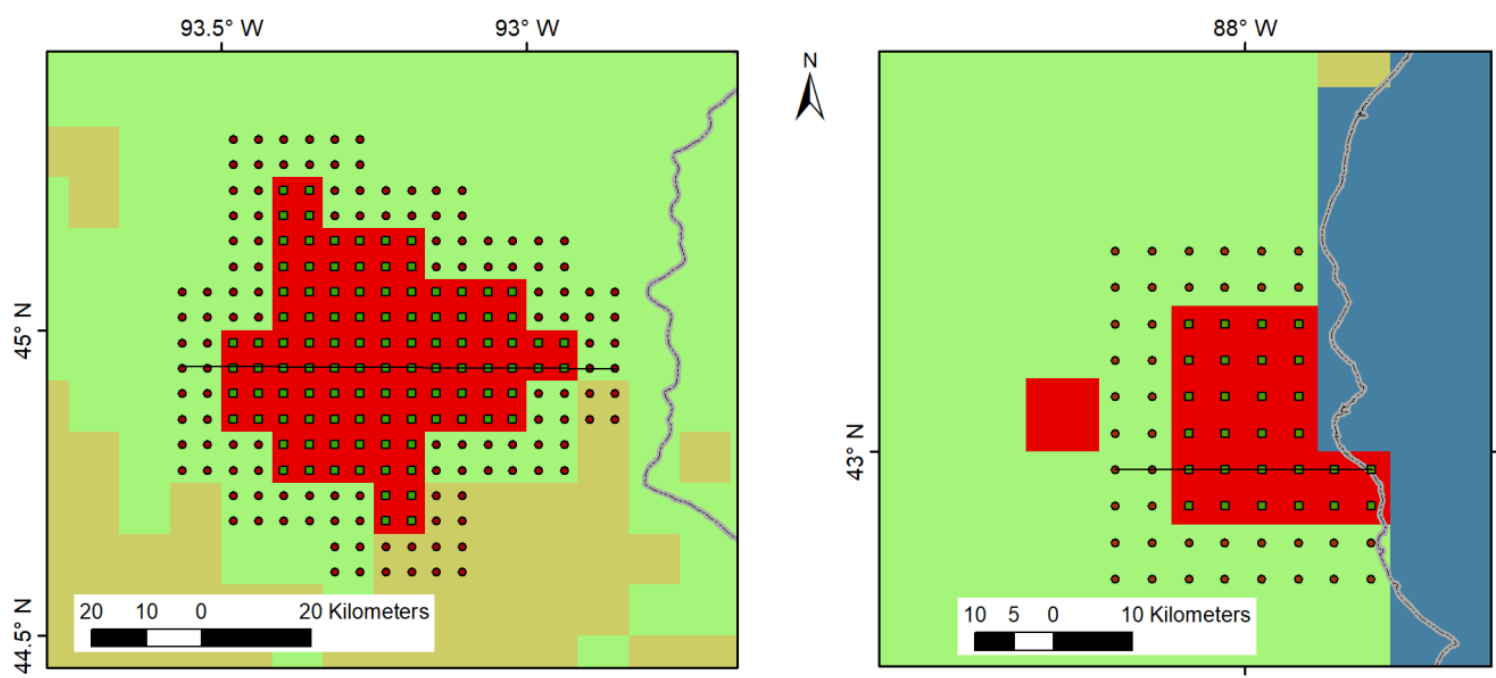

\section{Legend}

- Non-urban data points MODIS land cover

- Urban data points

Water

Deciduous Broadleaf forest State boundary

Evergreen Needleleaf forest Mixed forest Grasslands Permanent wetlands

(B)

Figure 1. Study area: (A) state boundaries of Minnesota and Wisconsin, data grid points, and MODIS 2012 land cover. (B) Urban and nonurban data points for Minneapolis-St. Paul (left) and Milwaukee (right). The horizontal lines are transects across urban and non-urban areas 


\section{Data and Methods}

\section{1) Meteorological Data}

This study used meteorological data produced by the Multivariate Adapted Constructed Analogs (MACA) statistical downscaling method (Abatzoglou and Brown 2012). The MACA statistical downscaling method utilized observed meteorological data to remove historical biases and harmonize geographical patterns in climate model output (University of Idaho n.d.(a)). Three data products are currently dispensed, and MACAv2-METDATA was selected for this study because it uses the newest version of the MACA method and is available for the study area. It contains daily downscaled meteorological and hydrological projections for the conterminous U.S. at a 4-km resolution. Detailed development processes are described in Abatzoglou (2013).

Temperature data were downloaded from the MACA data portal (University of Idaho n.d.(b)), and 11 of the 20 Coupled Model Intercomparison Project Phase 5 models listed on the page were selected: bcccsm1-1 (China), BNU-ESM (China), CanESM2 (Canada), CCSM4 (USA), CNRM-CM5 (France), CSIRO-Mk3-6-0 (Australia), GFDL-ESM2G (USA), HadGEM2-CC365 (United Kingdom), inmcm4 (Russia), IPSL-CM5A-LR (France), MIROC5 (Japan). Such a selection was made by choosing only one from each model family. Data were extracted from each of the models and heat stress indicators were computed for each model. The historical scenario data cover 1950-2005 and the RCP4.5 scenario data cover 2006-2099, and the data were analyzed for the entire time period of each scenario. The RCP (Representative Concentration Pathway) 4.5 scenario is an intermediate greenhouse gas forcing scenario where radiative forcing stabilizes at $4.5 \mathrm{Wm}^{-2}$ during the $21^{\text {st }}$ century (Cubasch et al. 2013).

The MACA data also contain humidity data, which are often considered in calculating heat stress indicators. When it comes to assessing the health effects, temperature alone can be insufficient (Chapman et al. 2017). The available humidity data in MACA are daily maximum and minimum relative humidity and daily mean specific humidity. Even though minimum relative humidity tends to occur at night rather than during daytime, there is no reliable information regarding its timing. Therefore, only temperature data were used to indicate heat stress like Wouters et al (2017).

\section{2) Indicators of Heat Stress}

Since the study focused on nighttime heat stress, heat stress indicators based on daily minimum temperature were used. Two types of heat stress indicators were considered, absolute and relative (Heo and Lee 2016). For the absolute indicator, the occasion when daily minimum temperature is at least 300 $\mathrm{K}\left(27^{\circ} \mathrm{C}\right)$ was chosen following Robinson $(2001)$. This was used to compute the frequency of hot nights. It is advisable to count at least two consecutive days of such days as an occasion of heat stress, but in this study, the number of days was counted when it occurred and decadal frequencies were calculated. The $95^{\text {th }}$ percentile of daily minimum temperature from the historical simulation was chosen for the relative indicator. Because there are many grid points in each study area, the lowest number was chosen for each domain for simplicity. This indicator was used to compute the duration of hot nights. The number of consecutive days above the $95^{\text {th }}$ percentile threshold was counted for duration.

The indicators were also calculated separately for urban and non-urban areas. The urban and non-urban areas were delineated based on the 5'x5'-resolution 2012 MODIS land cover data (Global Land Cover 
Facility). Contiguous MODIS urban pixels in each study area were designated as urban areas, and onepixel buffers around urban areas were designated as non-urban areas (Figure 1). The MACA grid points were selected within the urban and non-urban zones. Each MODIS pixel contains four MACA grid points.

\section{3) Transect Analysis}

The decadal frequency of hot nights was also analyzed along the transects traversing the cities (transects are shown in Figure 1B). The transects start in non-urban grid points west of the urban areas and end in non-urban grid points east of the urban areas. The frequency of hot nights was extracted from grid points on the transects and plotted as a graph.

\section{Results and Discussion}

\section{1) Substantial Increases in the Frequency of Hot Nights}

Across all grid points in Wisconsin and Minnesota from all the GCMs, the probability density functions of the frequency of daily minimum temperatures above $300 \mathrm{~K}$ are projected to fundamentally change between the historical and RCP4.5 simulations (Figure 2). In the historical simulations, the decadal frequency is essentially zero in both regions. In the RCP4.5 scenario, the peak of probability distribution appears at around 2-3, meaning 2-3 per decade is the most common occurrence in the entire dataset. Minnesota shows a larger range, with the maximum well past 30 per decade, whereas Wisconsin stops short of 25. Such large numbers came from CSIRO-Mk3-6-0. This study examined the entire $21^{\text {st }}$ century, but it is reported that anthropogenically-forced heat waves are likely to occur in the earlier part of the century (Lopez et al. 2018).
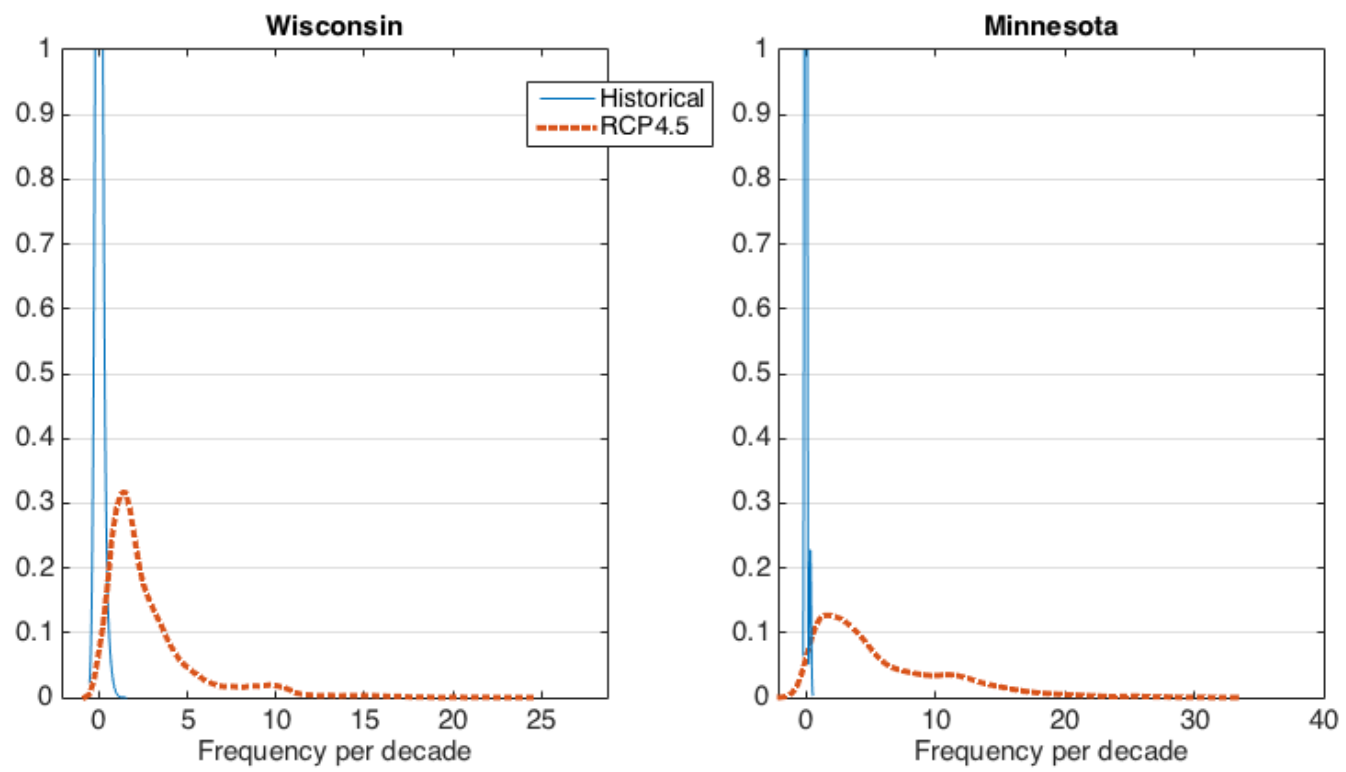

Figure 2. Probability density of the frequency of hot nights for Wisconsin and Minnesota study areas for the historical and RCP4.5 periods from all the GCMs.

The geographical distribution of the frequency averaged across the GCMs suggests the effect of the urban heat island in RCP4.5 (Figure 3). Both in Wisconsin and Minnesota, the probability across GCMs was almost zero in the historical simulation (Figure 2). In the RCP4.5 simulation, the frequency not only 
increased substantially but also particularly in major urban areas. The frequency in the center of MKE exceeds 8 per decade and other noticeable increases occur around cities, particularly along the lake shore. The frequency in the center of MSP exceeds 12 in RCP4.5, and the distribution is much more concentric than MKE due to its inland location. Overall, southeastern Minnesota is projected to experience hot nights more frequently than southeastern Wisconsin across the $21^{\text {st }}$ century.

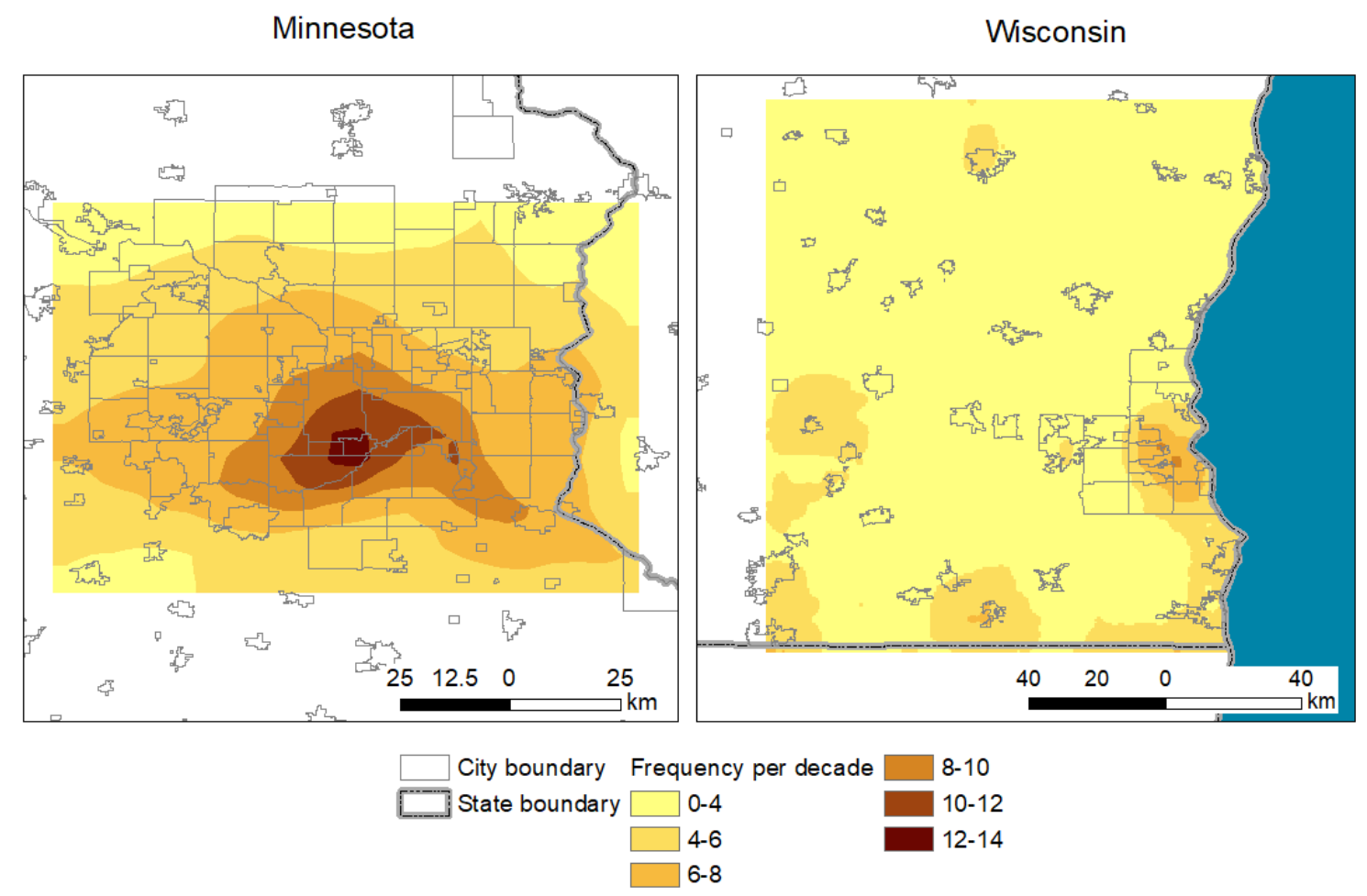

Figure 3. Averaged frequency of hot nights per decade for Wisconsin and for Minnesota in RCP4.5

The descriptive statistics of daily July minimum temperature numbers are quite similar between Minnesota and Wisconsin, and moderate differences are found between historical and RCP4.5 (Table 1). For Wisconsin, the mean and maximum for historical is $289.3 \mathrm{~K}\left(16.2{ }^{\circ} \mathrm{C}\right)$ and $301.6 \mathrm{~K}\left(28.5^{\circ} \mathrm{C}\right)$, respectively. The mean, standard deviation, and interquartile range are almost identical for Minnesota, but the maximum is about $1.4 \mathrm{~K}$ lower than that of Wisconsin. In RCP4.5, the mean increases by less than 3 $\mathrm{K}$, standard deviation by less than 0.2 , and interquartile range by less than $0.1 \mathrm{~K}$ both for Wisconsin and Minnesota. The maximum is projected to increase by more than $5 \mathrm{~K}$ for Wisconsin and $6 \mathrm{~K}$ for Minnesota, respectively.

Table 1. Descriptive statistics of daily July minimum temperature across GCMs and grid points

\begin{tabular}{l|l|l|l|l|l|l|l|l}
\hline & \multicolumn{4}{|l|}{ Historical } & \multicolumn{4}{l}{ RCP4.5 } \\
\cline { 2 - 9 } & Mean & SD & IQR & Max & Mean & SD & IQR & Max \\
\hline Wisconsin & 289.2982 & 3.4610 & 4.9861 & 301.5931 & 291.4781 & 3.5581 & 5.0051 & 307.1082 \\
\hline Minnesota & 289.7489 & 3.4267 & 4.9299 & 300.1304 & 292.1271 & 3.5925 & 4.9951 & 307.1259 \\
\hline
\end{tabular}

Note: SD stands for standard deviation and IQR stands for inter-quartile range.

\section{2) Larger Increases in the Frequency of Hot Nights in Urban than in Non-urban Areas}

In MKE, nights warmer than $300 \mathrm{~K}$ are almost non-existent in the historical period both in urban and nonurban areas (Figure 4). In urban areas, the maximum frequency is just above one, and is less than 0.8 in 
non-urban areas. The frequency substantially increases in RCP4.5, and the cumulative probability $(F(x))$ curves of urban and non-urban areas continue to diverge up to 0.8 of $F(x)$. In urban areas, approximately eight days per decade is larger than $80 \%$ of the data, whereas in non-urban areas, approximately four days is above $80 \%$ of the data, and eight days is above $90 \%$ of the data. The median values in RCP 4.5 are about five and 2.5 in urban and non-urban areas, respectively.
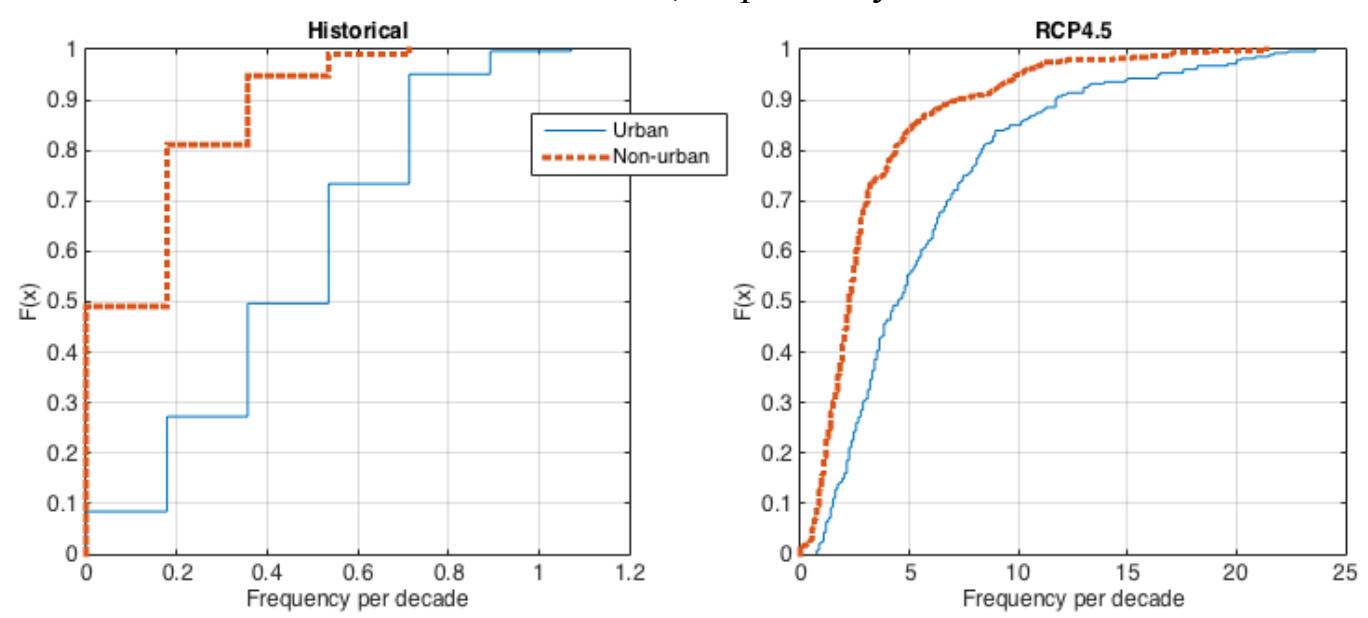

Figure 4. Cumulative probability distributions of decadal frequencies of hot nights between urban non-urban areas of MKE

In MSP, the range of decadal frequency is even smaller than MKE in the historical period. It is zero for non-urban areas, and zero for urban areas until $F(x)$ is 0.8 (Figure 5). In RCP4.5, the lines continue to diverge until $F(x)$ is 1 . The maximum exceeds 30 in urban areas and is approximately 22 in non-urban areas. The maximum frequency in RCP4.5 for non-urban areas is similar to MKE, but that for urban areas is much larger. The median for urban areas is approximately seven and that for non-urban areas is five.
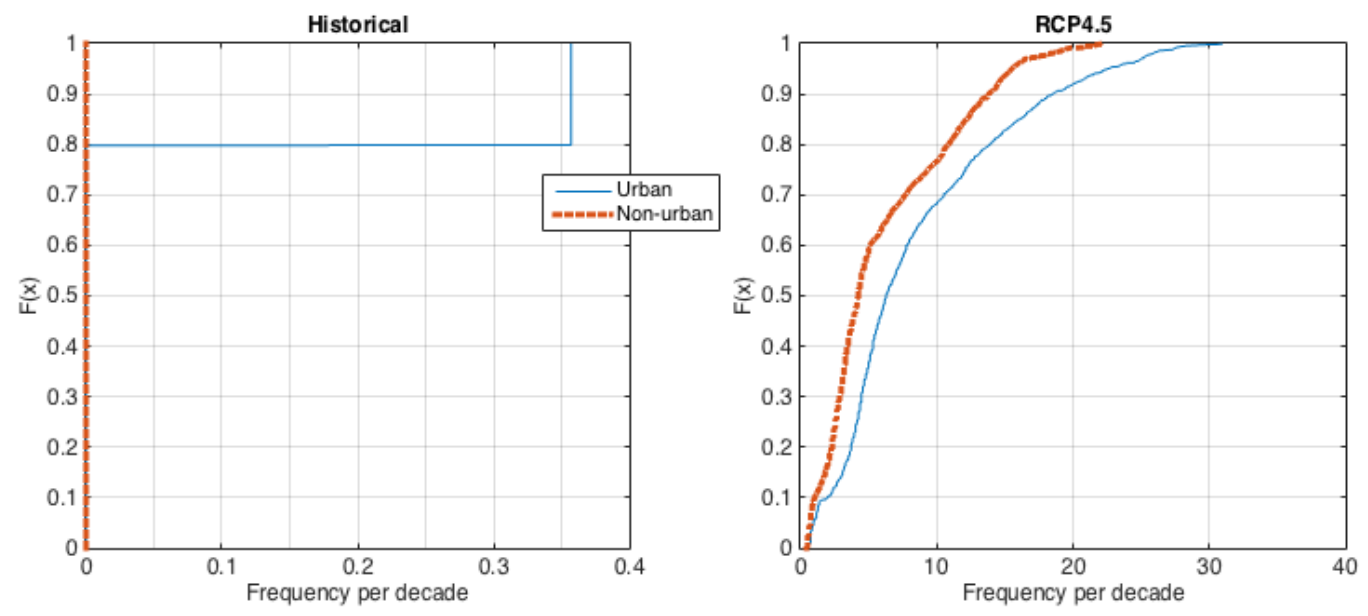

Figure 5. Same as Figure 4 but for MSP

The frequency of hot nights gradually increases along the transect (see Figure 1B) over urban land covers and decreases at the other end in the RCP4.5 simulation (Figure 6). Both in MKE and MSP, the frequency is just above zero over urban land covers in the historical simulation, but the frequency substantially increases in the RCP4.5 simulation and more so in MSP. Like in Figure 3, MSP shows more symmetric patterns than MKE, whereas in MKE the frequency in the east does not fall as low as in the west because the grid points over Lake Michigan were not included in the analysis.

Another important difference between MKE and MSP is found in the frequency over non-urban land covers. In MKE in RCP4.5 (upper-right panel), the frequency over non-urban land covers is about 1-3 in most of the models except one (CSIRO) with which the frequency hovers around 10. The frequency varies much more widely in MSP, with the lowest close to zero (HadGEM2) and the highest around 15 
(CSIRO and CCSM4), and is generally higher than MKE. The climate change impact on the frequency of hot nights is pronounced over urban land covers regardless of models. Even HadGEM2 (the line at the bottom of the lower-right panel) shows enhanced frequency in urban areas. The intensifying urban heat island effect in terms of heat stress calls for an action plan for mitigation. Because the current study assumed that the urban form would not change, urban design that could alleviate heat stress should be considered.

Figure 6 clearly demonstrates the moderating effect of Lake Michigan on temperatures. In MSP, which is located inland, the frequency of hot nights is lower than MKE in the historical simulation but much higher in RCP4.5, as mentioned previously. In the historical simulation, the effect of latitude appears to be larger, demonstrated by the lower frequency in MSP. In contrast, summer nighttime temperatures are generally projected to be lower in Wisconsin than in Minnesota in RCP4.5, suggesting the moderating effect of Lake Michigan. The result also suggests that the MACA dataset adequately reflects surface conditions and is useful for local-scale climate change impact studies.
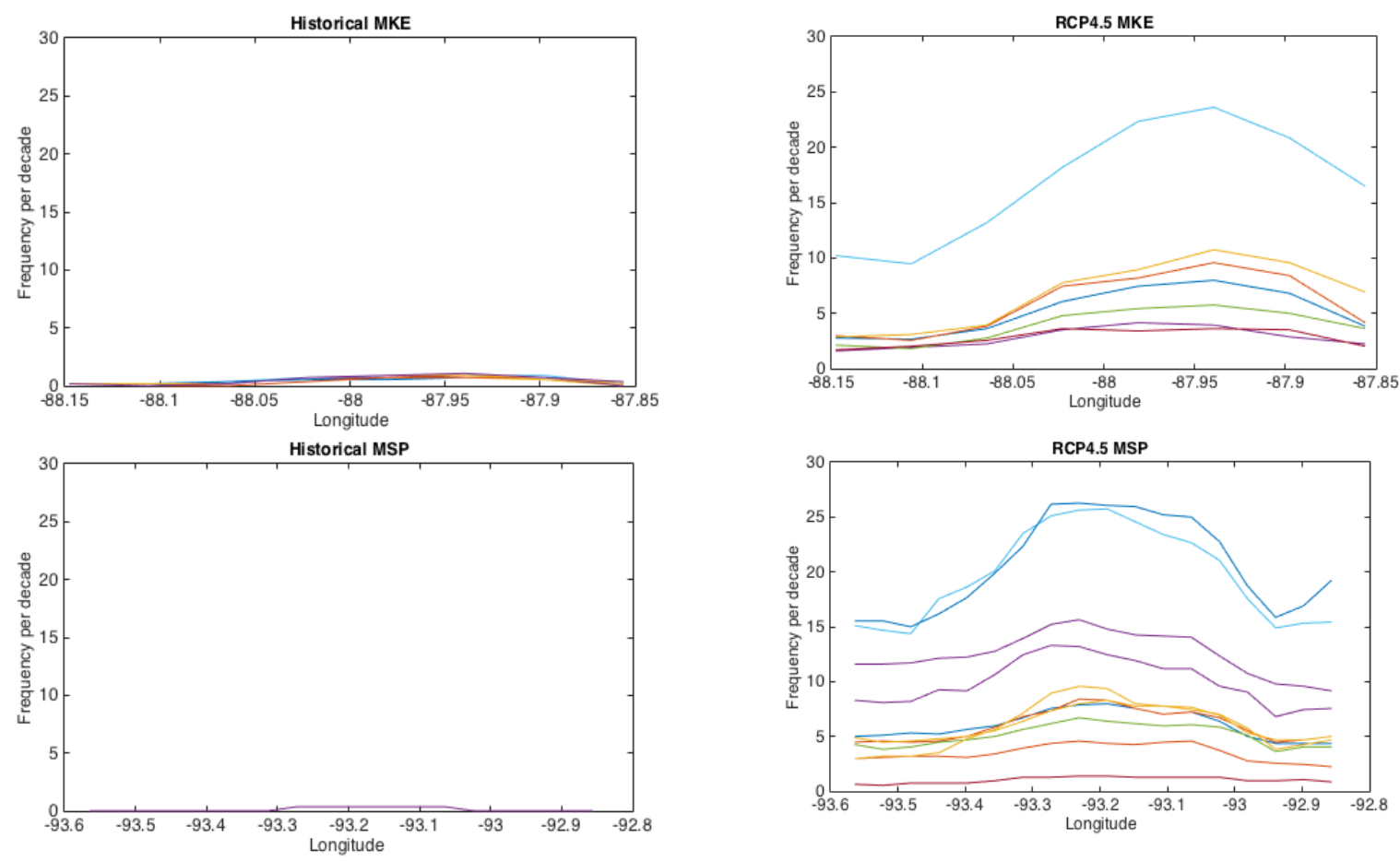

Figure 6. Frequency of hot nights per decade across the transect across urban and non-urban areas in MKE and MSP in the historical and

RCP4.5 simulations

\section{3) Longer Median Durations of Consecutive Hot Nights}

Median durations of consecutive days above the $95^{\text {th }}$ percentile threshold are most common at three days both in the historical and RCP4.5 runs across models and grid points but they are far more variable in RCP4.5, exceeding five (Minnesota) or six days (Wisconsin) (Figure 7). In other words, median durations longer than three days are much more likely in RCP4.5 than in historical. Maximum durations show much bigger changes between the historical and RCP4.5 runs. In both regions, the most frequent number is approximately 20 days in historical, but the peaks noticeably shift to the right in RCP4.5. In Wisconsin, maximum durations between 25 and 40 days have similar probabilities, and in Minnesota, approximately 35 days and 43 days have most probabilities. 

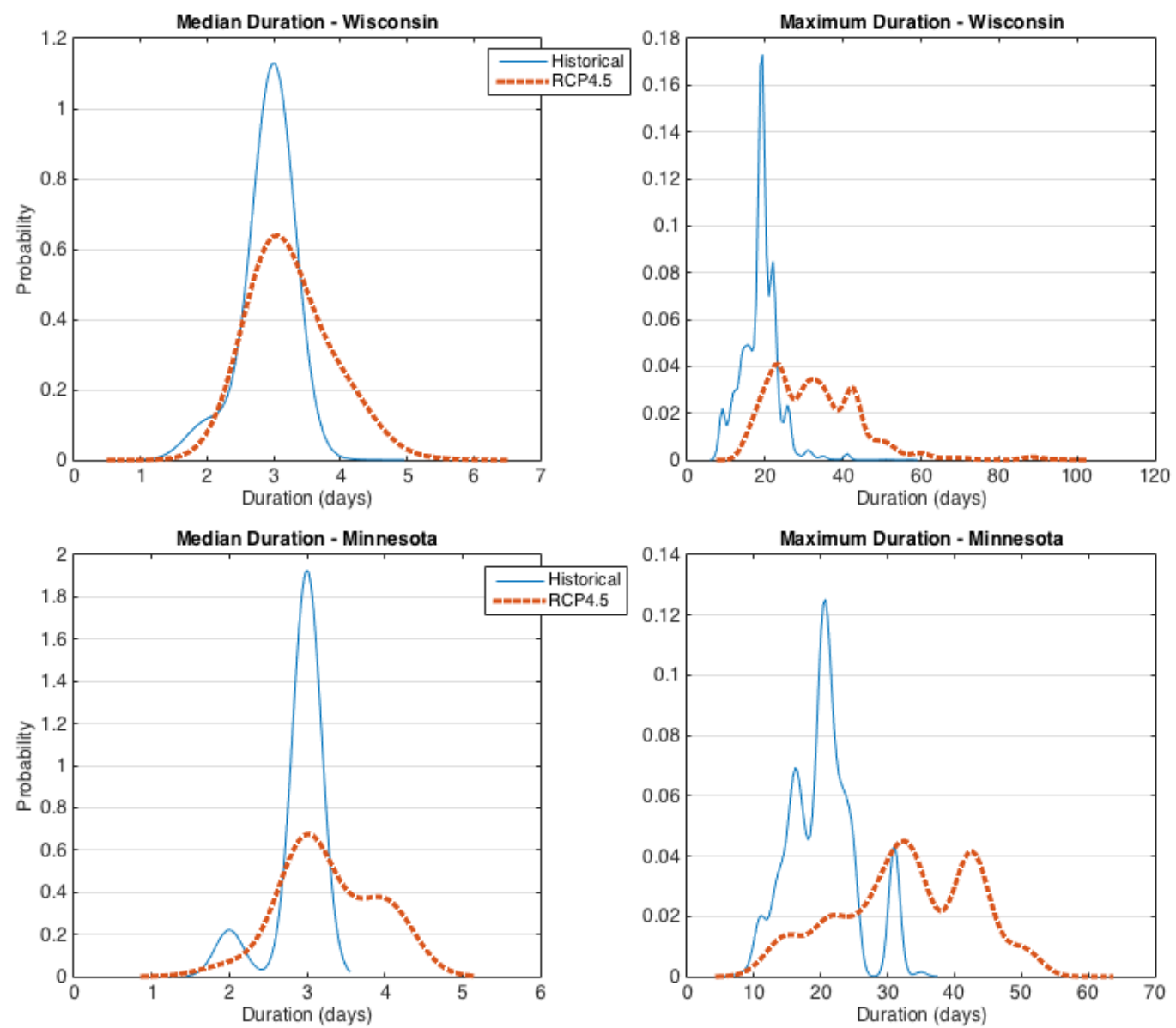

Figure 7. Median and maximum durations of hot nights for historical and RCP4.5

\section{Conclusions}

This study examined nighttime heat stress in the US Midwest using newly available high-resolution daily-scale climate model data, namely MACAv2-METDATA. An absolute and a relative indicator of heat stress was calculated for frequency and duration, respectively, for the historical and RCP4.5 scenarios. Overall, the dataset was found to be useful for research on heat stress and climate change in the context of urban heat island. The study also found that nighttime heat stress is projected to increase both in frequency and duration, and the urban heat island effect in terms of heat stress is projected to intensify in the future.

Even though the study region has not received much attention regarding heat stress, climate change is likely to affect the region to a non-negligible extent, and mitigations plans should be prepared accordingly. Particular attention should be paid to inner city areas where the impacts are larger than outlying areas and populations of lower socio-economic status are clustered. Further research is warranted that considers socio-economic conditions of the population in the area and the role of humidity in heat stress. 


\section{Acknowledgement}

The U.S. National Science Foundation provided via the American Association of Geographers financial support for the author's trip to the International Geographical Union Regional Conference in Quebec City, Canada in 2018 where the research was presented.

\section{References}

Abatzoglou, J. T., and T. J. Brown. 2012. A comparison of statistical downscaling methods suited for wildfire applications. International Journal of Climatology 32:772-780.

Abatzoglou, J. T. 2013. Development of gridded surface meteorological data for ecological applications and modelling. International Journal of Climatology 33:121-131.

Argueeso, D., J. P. Evans, A. J. Pitman, and A. Di Luca. 2015. Effects of City Expansion on Heat Stress under Climate Change Conditions. Plos One 10:e117066.

Chapman, S., J. E. M. Watson, A. Salazar, M. Thatcher, and C. A. McAlpine. 2017. The impact of urbanization and climate change on urban temperatures: a systematic review. Landscape Ecology 32:1921-1935.

Choi, W. 2008. Climatic Data, Reanalysis. In Encyclopedia of Global Warming and Climate Change, ed. S. G. Philander, 243-245. Thousand Oaks, California: SAGE Publications, Inc.

Choi, W., A. Keuser, and S. Becker. 2012. Identification of mid-latitudinal regional and urban temperature variabilities based on regional reanalysis data. Theoretical and Applied Climatology 107:87-98.

Cubasch, U., D. Wuebbles, D. Chen, M. C. Facchini, D. Frame, N. Mahowald, and J. -. Winther. 2013. Introduction. In Climate Change 2013: The Physical Science Basis. Contribution of Working Group I to the Fifth Assessment Report of the Intergovernmental Panel on Climate Change. ed. T. F. Stocker, D. Qin, G.-K. Plattner, M. Tignor, S. K. Allen, J. Boschung, A. Nauels, Y. Xia, V. Bex and P. M. Midgley, Cambridge, United Kingdom and New York, NY, USA: Cambridge University Press.

Fischer, E. M., K. W. Oleson, and D. M. Lawrence. 2012. Contrasting urban and rural heat stress responses to climate change. Geophysical Research Letters 39(3). DOI: 10.1029/2011GL050576.

Fleming, A., R. Michaelson, A. Youssef, O. Holmes, C. Fonbuena, and H. Robertson. 2018. Heat: the next big inequality issue. The Guardian. 13 August 2018.

Global Land Cover Facility. MODIS Land Cover. Available from http://glcf.umd.edu/data/lc/ (last accessed 29 August 2018).

Guerreiro, S. B., R. J. Dawson, C. Kilsby, E. Lewis, and A. Ford. 2018. Future heat-waves, droughts and floods in 571 European cities. Environmental Research Letters 13:034009.

Heo, I., and S. Lee. 2016. Characteristics of Heat Waves and Cold Spells in South Korea. Journal of Climate Research 11:151-167.

Kim, J., K. R. Kim, C. C. Lee, S. C. Sheridan, L. S. Kalkstein, and B. Kim. 2016. Analysis of Occurrence Distribution and Synoptic Pattern of Future Heat Waves in Korea. Journal of Climate Research $11: 15-27$.

Kirtman, B., S. B. Power, J. A. Adedoyin, G. J. Boer, R. Bojariu, I. Camilloni, F. J. Doblas-Reyes, A. M. Fiore, M. Kimoto, G. A. Meehl, M. Prather, A. Sarr, C. Schär, R. Sutton, G. J. van Oldenborgh, G. Vecchi, and H. J. Wang. 2013. Near-term Climate Change: Projections and Predictability. In Climate Change 2013: The Physical Science Basis. Contribution of Working Group I to the Fifth Assessment Report of the Intergovernmental Panel on Climate Change. ed. T. F. Stocker, D. Qin, G. -. Plattner, M. Tignor, S. K. Allen, J. Boschung, A. Nauels, Y. Xia, V. Bex and P. M. Midgley, Cambridge, UK and New York, USA: Cambridge University Press.

Li, Y., T. Ren, P. L. Kinney, A. Joyner, and W. Zhang. 2018. Projecting future climate change impacts on heat-related mortality in large urban areas in China. Environmental Research 163:171-185. 
Lopez, H., R. West, S. Dong, G. Goni, B. Kirtman, S. Lee, and R. Atlas. 2018. Early emergence of anthropogenically forced heat waves in the western United States and Great Lakes. Nature Climate Change. DOI: 10.1038/s41558-018-0116-y

Ma, S., A. Pitman, J. Yang, C. Carouge, J. P. Evans, M. Hart, and D. Green. 2018. Evaluating the Effectiveness of Mitigation Options on Heat Stress for Sydney, Australia. Journal of Applied Meteorology and Climatology 57:209-220.

Meehl, G. A., T. F. Stocker, W. D. Collins, P. Friedlingstein, A. T. Gaye, J. M. Gregory, A. Kitoh, R. Knutti, J. M. Murphy, A. Noda, S. C. B. Raper, I. G. Watterson, A. J. Weaver, and Z.-C. Zhao. 2007. Global Climate Projections. In Climate Change 2007: The Physical Science Basis. Contribution of Working Group I to the Fourth Assessment Report of the Intergovernmental Panel on Climate Change, ed. S. Solomon, D. Qin, M. Manning, Z. Chen, M. Marquis, K. B. Averyt, M. Tignor and H. L. Miller, 747-845. Cambridge, UK and New York, USA: Cambridge University Press.

Meehl, G., and C. Tebaldi. 2004. More intense, more frequent, and longer lasting heat waves in the 21st century. Science 305:994-997.

Mora, C., B. Dousset, I. R. Caldwell, F. E. Powell, R. C. Geronimo, C. Bielecki, C. W. W. Counsell, B. S. Dietrich, E. T. Johnston, L. V. Louis, M. P. Lucas, M. M. McKenzie, A. G. Shea, H. Tseng, T. W. Giambelluca, L. R. Leon, E. Hawkins, and C. Trauernicht. 2017. Global risk of deadly heat. Nature Climate Change 7:501.

National Climatic Data Center. n.d. Summary of Monthly Normals. Available from https://files.dnr.state.mn.us/natural_resources/climate/twin_cities/msp_normals_1981-2010.pdf(last accessed 30 August 2018).

Okamoto-Mizuno, K., and K. Mizuno. 2012. Effects of thermal environment on sleep and circadian rhythm. Journal of Physiological Anthropology 31:14-14.

Oleson, K. W., G. B. Anderson, B. Jones, S. A. McGinnis, and B. Sanderson. 2018. Avoided climate impacts of urban and rural heat and cold waves over the US using large climate model ensembles for RCP8.5 and RCP4.5. Climatic Change 146:377-392.

Oleson, K. W., A. Monaghan, O. Wilhelmi, M. Barlage, N. Brunsell, J. Feddema, L. Hu, and D. F. Steinhoff. 2015. Interactions between urbanization, heat stress, and climate change. Climatic Change 129:525-541.

Robinson, P. J. 2001. On the Definition of a Heat Wave. Journal of Applied Meteorology 40:762-775.

Smith, T. T., B. F. Zaitchik, and J. M. Gohlke. 2013. Heat waves in the United States: definitions, patterns and trends. Climatic Change 118:811-825.

Uejio, C. K., O. V. Wilhelmi, J. S. Golden, D. M. Mills, S. P. Gulino, and J. P. Samenow. 2011. Intraurban societal vulnerability to extreme heat: The role of heat exposure and the built environment, socioeconomics, and neighborhood stability. Health \& place 17:498-507.

University of Idaho. n.d.(a) Multivariate Adaptive Constructed Analogs (MACA) Datasets. Available from https://climate.northwestknowledge.net/MACA/index.php (last accessed 30 August 2018).

. n.d.(b) MACA Data Portal. Available from https://climate.northwestknowledge.net/MACA/data_portal.php (last accessed 30 August 2018).

Wouters, H., K. De Ridder, L. Poelmans, P. Willems, J. Brouwers, P. Hosseinzadehtalaei, H. Tabari, S. Vanden Broucke, N. P. M. van Lipzig, and M. Demuzere. 2017. Heat stress increase under climate change twice as large in cities as in rural areas: A study for a densely populated midlatitude maritime region. Geophysical Research Letters 44:8997-9007.

Young, J. 2007. Milwaukee General Mitchell Field (475479, WBAN No. 14893). In Wisconsin State Climatology Office [database online]. Available from http://www.aos.wisc.edu/\%7Esco/climhistory/stations/475479.html (last accessed 30 August 2018).

Zhao, L., M. Oppenheimer, Q. Zhu, J. W. Baldwin, K. L. Ebi, E. Bou-Zeid, K. Guan, and X. Liu. 2018. Interactions between urban heat islands and heat waves. Environmental Research Letters 13:034003. 